\section{Military Technical College Kobry El-Kobbah, Cairo, Egypt}

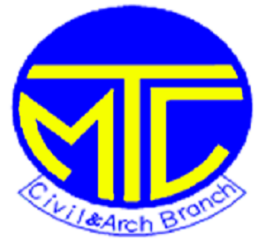
$9^{\text {th }}$ International Conference on Civil and Architecture Engineering ICCAE-9-2012

\title{
Numerical study of lightweight sandwich panels under explosion using rigid polyurethane foam and vulcanized rubber M. Rashad ${ }^{1}$, M. A. Elwahab ${ }^{2}$, S. Y. Mahfoz ${ }^{3}$, M. S. Amin ${ }^{4}$
}

Abstract

Structural weight reduction is one of the main design objectives in structural engineering. Various concepts have been proposed to reduce weight of military tunnels protecting layers and armored doors. Among them, application of sandwich sheets which comprise of two face sheets and low-density core materials which offers a significant weight reduction, high resistance against blast loads, and the ability to withstand repetitive blast loa ds.

In this paper, numerical investigations were conducted using 3D nonlinear finite element simulations with commercial ANSYS AUTODYN software. A number of peripherally simply supported (from all sides) nonmetallic core sandwich panels with either rigid $\mathrm{p}$ olyurethane foam (RPF) or vulcanized rubber (VR) cores were studied. A parametric study was carried out to study the behavior of these types of sandwich panels against blast load. Different thickness for different core materials were tested namely 5, 10, 15, and $20 \mathrm{~cm}$. Sandwich Panels were subjected to different blast charges of 1,5 and $10 \mathrm{~kg}$ TNT at fixed standoff distance 1 meter.

It was concluded that the behavior of high density RPF sandwich panel is better than that of VR sandwich panel. Using rigid polyurethane foam instead of vulcanized rubber as a core material decreases the maximum displacement by an average value $48.67 \%$, for the three different blast loads, which is good displacement reduction.

Keywords: 3D nonlinear finite element analysis, rigid polyurethane foam, vulcanized rubber, blast loads.

\section{Introduction}

It is very difficult to conduct field blast tests in every site due to the cost, environmental constraints and danger which may be occurred due to explosion process . Beshara [1] had identified various contributions to the understanding and modeling of the blast loading on above ground structures. In recent years, theoretical response methods have been augmented by the advent of non -linear

\footnotetext{
${ }^{1}$ Post graduate student: Civil Engineering Department, Military Technical College, Cairo, Egypt.

${ }^{2} \mathrm{Ph}$. D. Director of T.R.C. Cairo, Egypt.

${ }^{3}$ Assistance Professor: Civil Engineering Department, Military Technical College, Cairo, Egypt.

${ }^{4} \mathrm{Ph}$. D. Lecturer: Civil Engineering Department, Military Technical College, Cairo, Egypt .
} 
explicit three dimensional finite element codes such as ANSY S AUTODYN [2]. Calculations based on these codes have been shown to give good agreement with experimental data for a range of blast- structure problems.

Metallic sandwich panels with a cellular core such as honeycomb, stiffener or truss have the capability of dissipating considerable energy by large plastic deformation under dynamic loading. Those types of sandwich panels have a heavy weight compared to nonmetallic core (foam and polymer) sandwich panels. Experimental, computational and analytical investig ations were conducted on metallic sandwich panels, with either honeycomb or aluminum foam cores, to resist blast loads [3-7].

Concerning non-metallic materials, Available data from recent experiments [8-11] had shown that rigid polyurethane foam (RPF) has a remarkable capability to absorb and dissipate blast wave energy. A series of investigations on the application of RPF, focused on evaluating the effect of the foam density on the capability to absorb the impact of explosive blast waves, were conducted during the past two decades [12-14]. Polyurethane foam (RPF) layers used to retrofit the sandwich armed steel doors were shown to be an effective tool to resist the blast wave propagation [15]. Experimental investigations showed that rubber coating provides additional damping for the model, which is helpful in reducing high-frequency response [16]. Rubber modification can suppress spallation, markedly improving high rate impact resistance [17].

In this paper, nonlinear finite element simulations were conduct ed using commercial ANSYS AUTODYN software to investigate the behavior of two different types of lightweight sandwich panels subjected to different explosion loads. These two types are RPF core sandwich panel and VR core sandwich panel. Twenty four finite element models were created to simulate the dynamic response of these two types of lightweight sandwich panels subjected to different explosion loads. Each type of lightweight sandwich panels has twelve finite element models. In all the twenty four finite element models, the displacement-time histories were obtained by subjecting each type of lightweight sandwich panels with different core thickness $(5,10,15$, and 20$) \mathrm{cm}$ to different values of explosion charges $(1,5$ and $10 \mathrm{~kg}$ TNT) at the same standoff distance 1 meter

\section{Verification of the finite element model}

Numerical analysis was performed to assess the accuracy of the proposed finite element model. A. A. Mostafa1 [20] applied field blast tests on armored doors. One of those tests was applied to measure pressure-time history created from hitting a honeycomb armored door with blast wave resulted from explosion of $1 \mathrm{Kg}$ TNT at standoff distance $1 \mathrm{~m}$. One of the target points is chosen to be in the center of the front plate of honeycomb armored door which is na med as point (1). By applying a numerical model simulating this field blast test, the result shows that the reading obtained by the field blast test agrees well with that estimated by the FEA. The trend of the pressure-time history hit the armored door obt ained by both the field measurements and the FEA is the same as illustrated in figure (1).

\section{Sandwich panels model description}


The studied lightweight sandwich panels are composed of two outer steel sheet plates which are square in shape of $1.0 \mathrm{~m}$ height, $1.0 \mathrm{~m}$ width and $3 \mathrm{~mm}$ thickness. The in-between spacing (core spacing) between these two steel sheet plates is filled with rigid polyurethane foam or vulcanized rubber. This core spacing has different values of thickness $(5,10,15$, and 20) $\mathrm{cm}$. Two steel sheet plates are jointed (adhered) to core material either rigid polyurethane foam or vulcanized rubber. Rare steel sheet plate (back plate) is simply supported, prevented from translating in the blast wave direction, at the perimeter nodes. Explosion material used in simulating explosion process is TNT of different weights $(1,5$ and $10 \mathrm{~kg}$ TNT) at the same standoff distance 1 meter. For all finite element models, the displacement-time history is measured at the center of the rare steel sheet plate. Figure (2) shows a description of the studied light weight sandwich panel geometry for $5 \mathrm{~cm}$ core thickness and $1 \mathrm{~kg}$ TNT at standoff distance $1 \mathrm{~m}$. All finite element models have the same boundary conditions as shown in figure (3).

The mechanical properties of steel use $d$ in FEA are Poisson's ratio $v=3.0$; averaged mass density of steel $7900 \mathrm{~kg} / \mathrm{m}^{3}$; Elastic modulus $E=2350 \mathrm{t} / \mathrm{cm}^{2}$; and yield strength $\mathrm{f}_{\mathrm{y}}=3500 \mathrm{~kg} / \mathrm{cm}^{2}$. The mechanical properties of RPF used in this study are averaged mass density of RPF layer is $1.265 \mathrm{gm} / \mathrm{cm}^{3}$; Poisson's ratio $v=0.3$; Bulk modulus $\mathrm{E}_{\mathrm{i}}=20 \times 10^{5} \mathrm{KPa}$; Shear modulus is $5 \times 10^{3}$ $\mathrm{KPa}$; Principle tensile failure stress is $3.45 \times 10^{4} \mathrm{KPa}$. The mechanical properties of VR used in this study are averaged mass density of vulcanized rubber layer is $1.0 \mathrm{gm} / \mathrm{cm}^{3}$; Poisson's ratio $v=0.5$.

\section{Numerical modeling}

In this numerical modeling, air and TNT were simulated by Euler processor. A benefit of using Euler-FCT, to represent air, is that there is no grid distortion in this element type. Rigid polyurethane foam and vulcanized rubber were simulated by Lagrange processor. The Lagrange numerical mesh deforms and moves. This means that no material was transported between elements. Steel sheet plates were simulated by shell element. Shell element permits translation in the three directions and rotation around the three directions. Shell element was used to model both the membrane (in-plane) and the bending (out-of-plane) behavior of the steel sheet plates. The shell element is used to model thin structural elements at which the use of the standard Lagrange formulation would impose a very small time step during analysis possesses.

\section{Behavior of different lightweight sandwich panels under blast loads}

Numerical analysis was done to quantify and investigate the displacement -time histories obtained by subjecting high density RPF and VR sandwich panels to different blast loads. Different core thickness namely 5,10,15, and $20 \mathrm{~cm}$ and different values of explosion charges of 1,5 and $10 \mathrm{~kg}$ TNT at fixed standoff distance 1 meter were simulated. The capability of RPF and VR to resist blast loads and the effect of changing the thickness of core on the behavior of sandwich panels were studied. Conclusions were given on what type of sandwich panels is better to resistant blast loads. Figures $(4,5$, and 6) illustrate displacement-time histories of point (1) of RPF core sandwich panels subjected to 1,5 and $10 \mathrm{~kg}$ TNT respectively with thickness $(5,10,15$ and 20$) \mathrm{cm}$ at standoff $1 \mathrm{~m}$. Table (1) shows the percentages of maximum displacement va lues of RPF sandwich panels at the same boundary conditions mentioned above.

Figures $(7,8$, and 9) illustrate displacement-time histories of point (1) of VR core sandwich panels subjected to 1,5 and $10 \mathrm{~kg}$ TNT respectively with thickness $(5,10,15$ and 20) $\mathrm{cm}$ at standoff $1 \mathrm{~m}$. Table (2) shows the percentages of maximum displacement values of VR sandwich panels at the same boundary conditions mentioned above. 
Figures (10 and 11) illustrate the relationship between the maximum displacement values and the thickness of core of high density RPF and VR sandwich panels respectively at different blast load values 1,5 and $10 \mathrm{~kg}$ TNT.

Figures (12, 13, and 14) present a comparison between displacement-time histories of point (1) of RPF and VR core sandwich panels subjec ted to 1,5 and $10 \mathrm{~kg}$ TNT respectively with thickness 20 $\mathrm{cm}$. Table (3) shows the reduction percentages of maximum displacement values occurred due to the replacement of $20 \mathrm{~cm}$ vulcanized rubber with $20 \mathrm{~cm}$ rigid polyurethane foam as a core material of sandwich panel subjected to three different blast loads.

Figure (15) illustrates the relationship between the maximum displacement values of RPF and VR core sandwich panels to the TNT weight at fixed standoff distance 1 meter.

\section{Conclusions}

It is worth mentioning that the thickness of sandwich panel core material is found to be a significant factor affecting the response of sandwich panel under blast loads. The displacement was found to decrease with time as a result of the demolition of the blast pressure with time. Also it was noticed that the damping rate of the models was increased by increasing the thickness of core.

It was found that the slop of the maximum displacement curve against the thickness of core for high density RPF sandwich panel is greater than that of VR sandwich panel for the three different blast loads. It means that the rate of decreasing the maximum displacement value of high density RPF sandwich panel, by increasing core thickness for the same blast load, is greater than that of Vulcanized Rubber core sandwich panel.

It was concluded that the behavior of high density RPF sandwich panel is better than that of VR sandwich panel. Using rigid polyurethane foam instead of vulcanized rubber as a core material decreases the maximum displacement by an average value $48.67 \%$, for the three different blast loads, which is good displacement reduction. High density RPF sandwich panel behaves elastically for a good range of blast loads while VR sandwich panel goes to plastic zone for smaller range of blast loads.

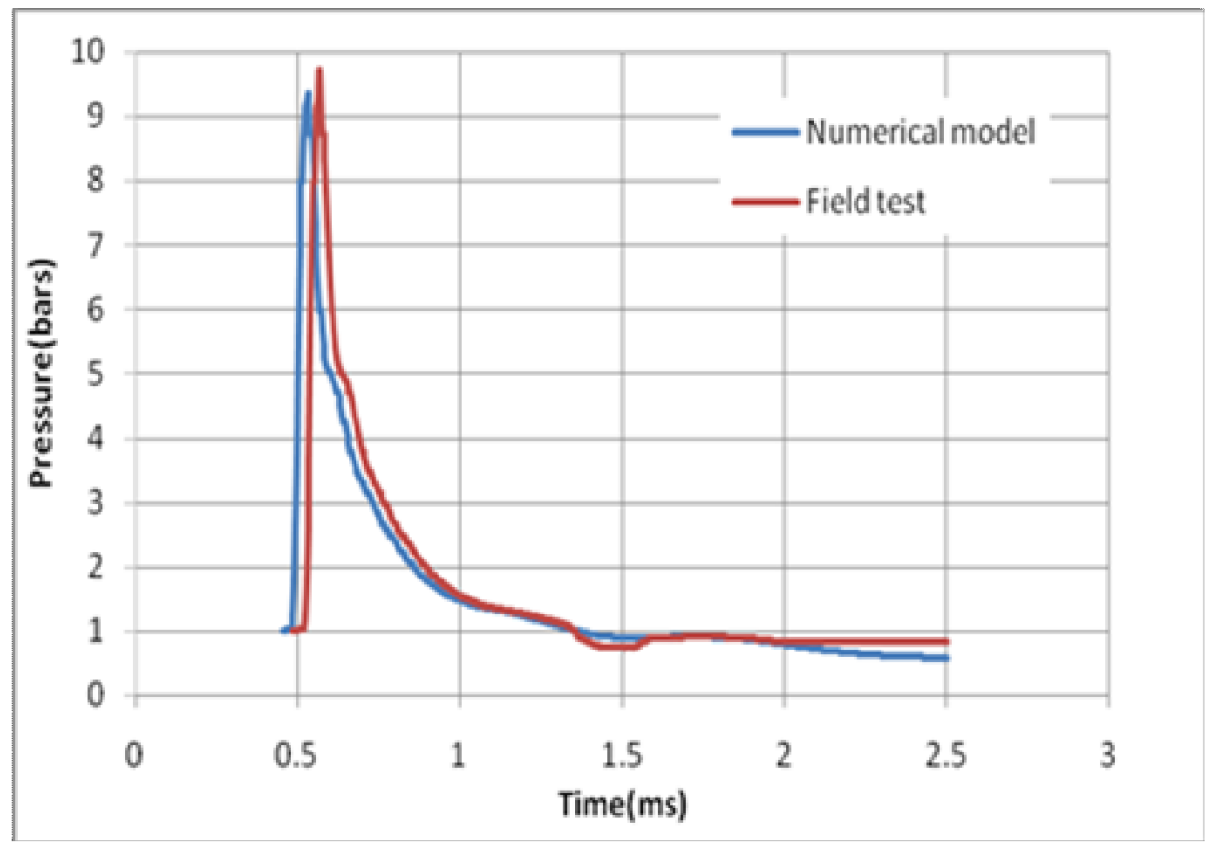


Figure (1): Pressure-time history at point (1). 


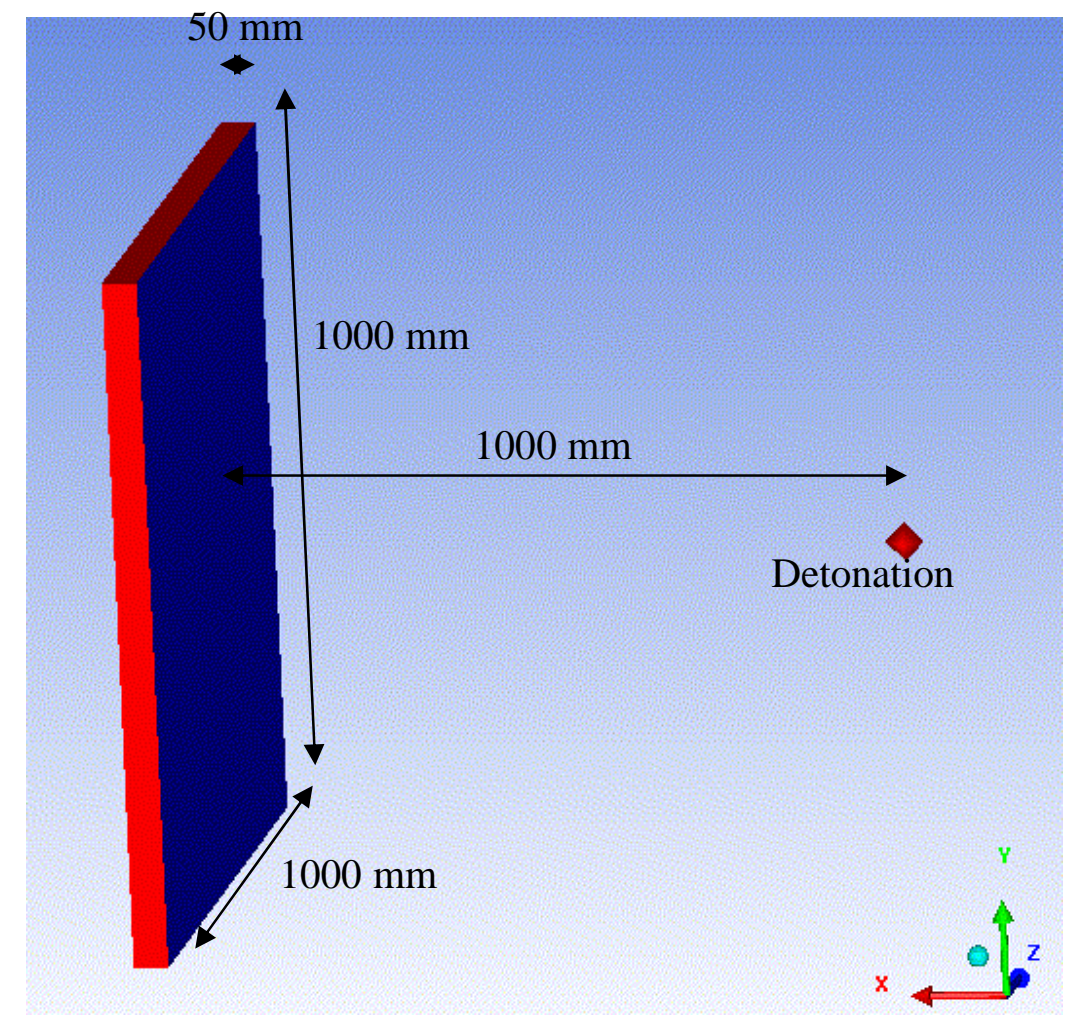

Figure (2): Sandwich panels model description .

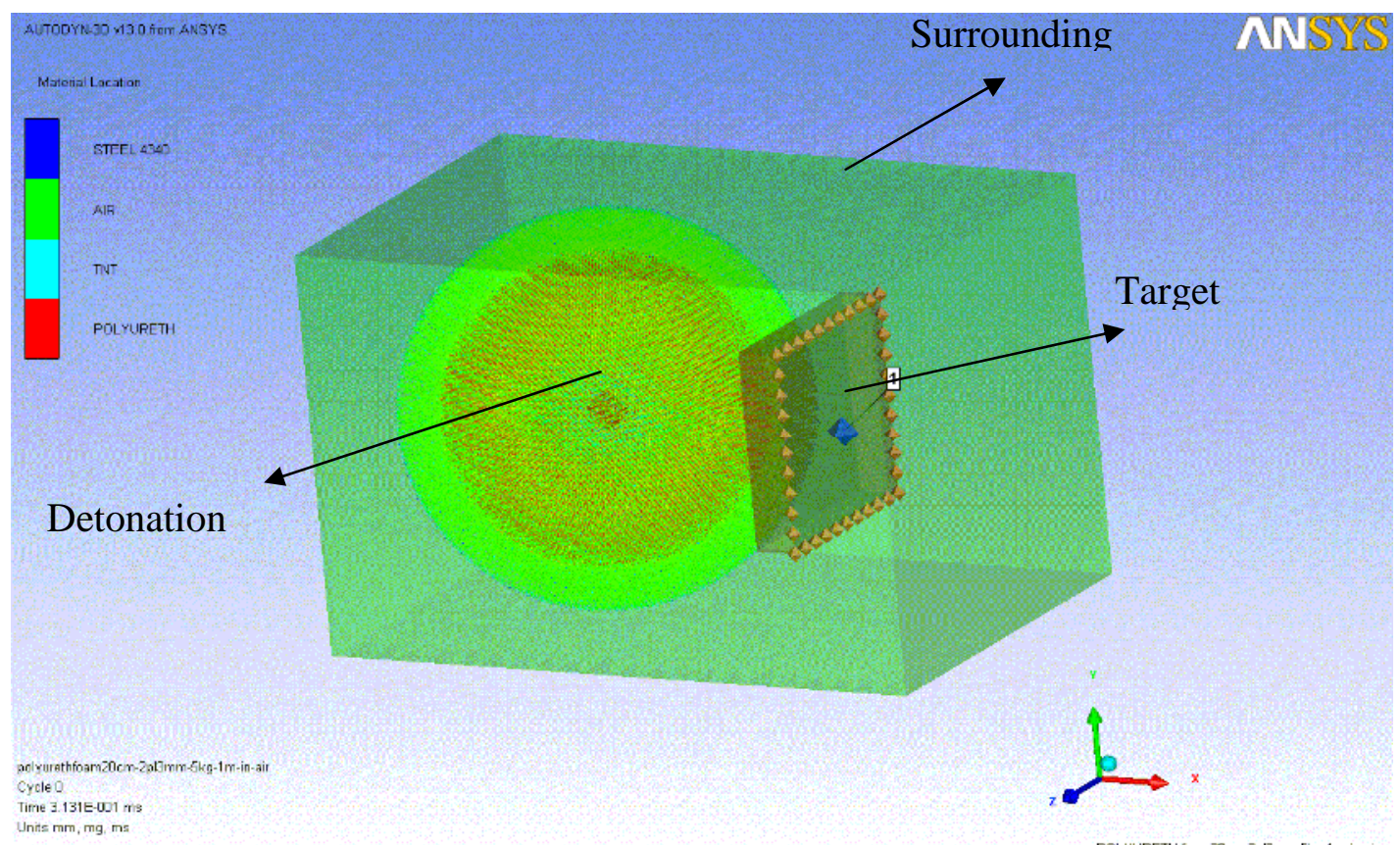

Figure (3): The boundary conditions of sandwich panel and air media which contain explosion sphere. 


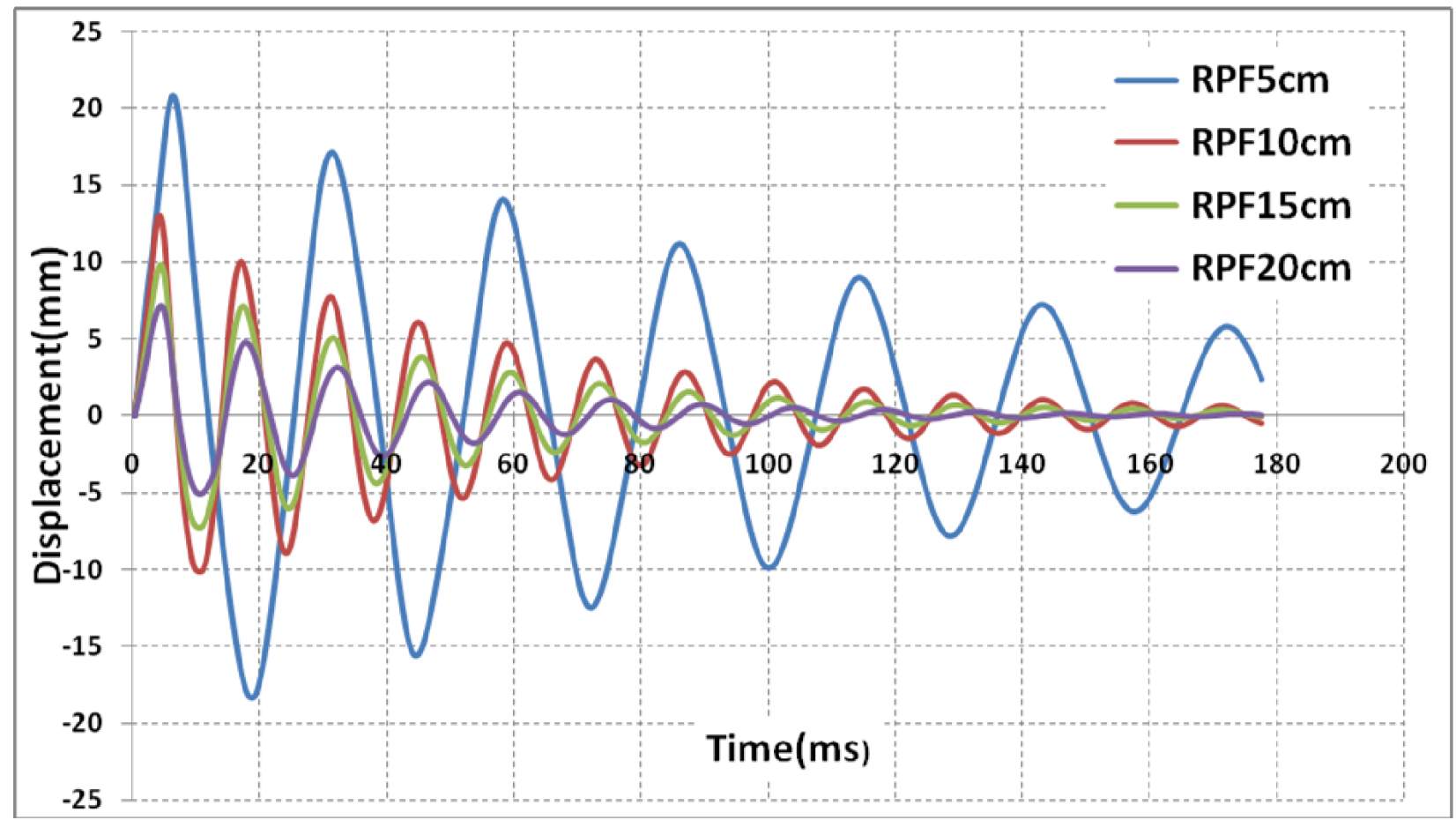

Figure (4): Displacement-time histories of point (1) of RPF sandwich panels with thickness $(5,10$, 15 and20) $\mathrm{cm}$ subiected to $1 \mathrm{Kg}$ TNT at standoff $1 \mathrm{~m}$.

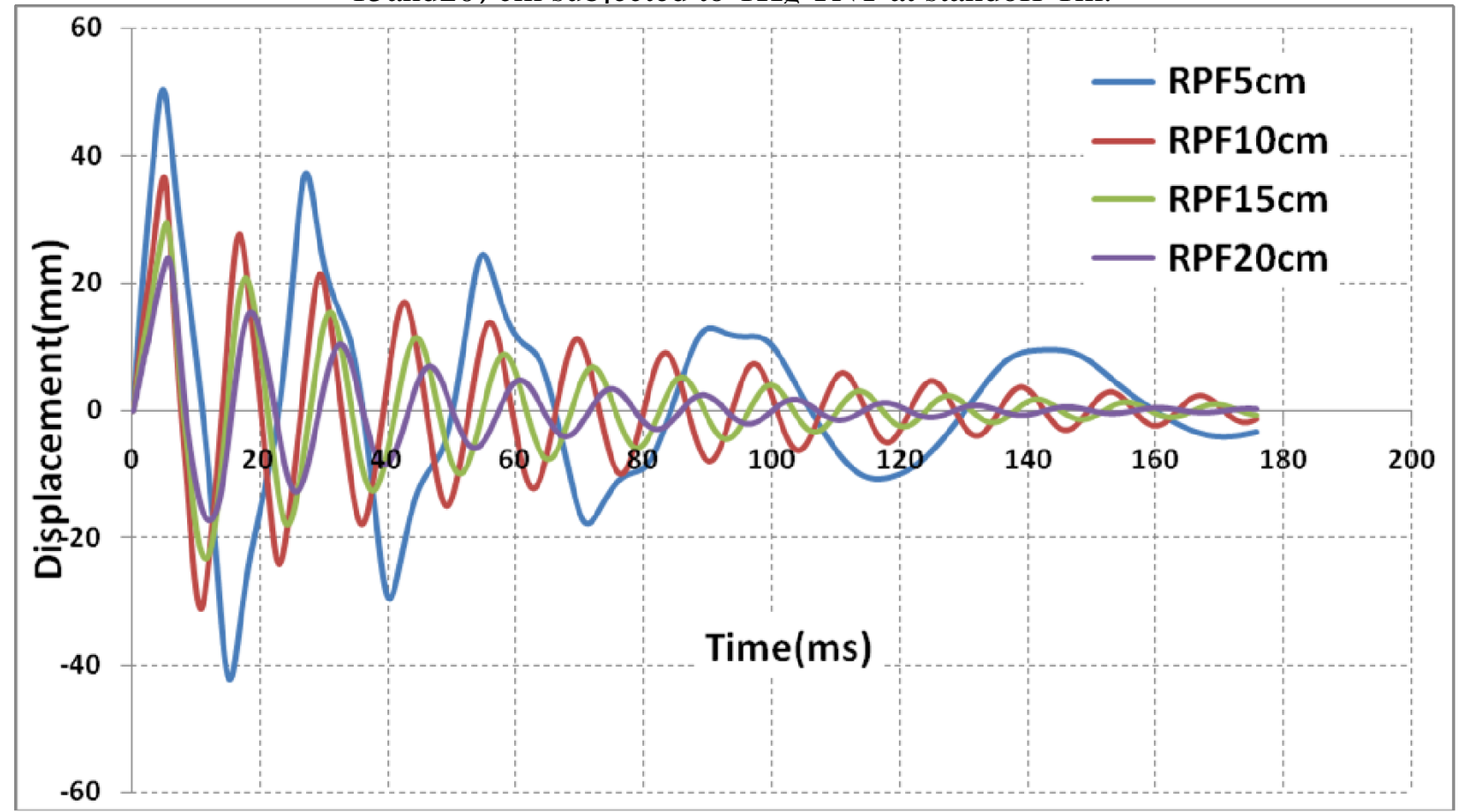

Figure (5): Displacement-time histories of point (1) of RPF sandwich panels with thickness $(5,10$, 15 and20) $\mathrm{cm}$ subjected to $5 \mathrm{Kg}$ TNT at standoff $1 \mathrm{~m}$. 


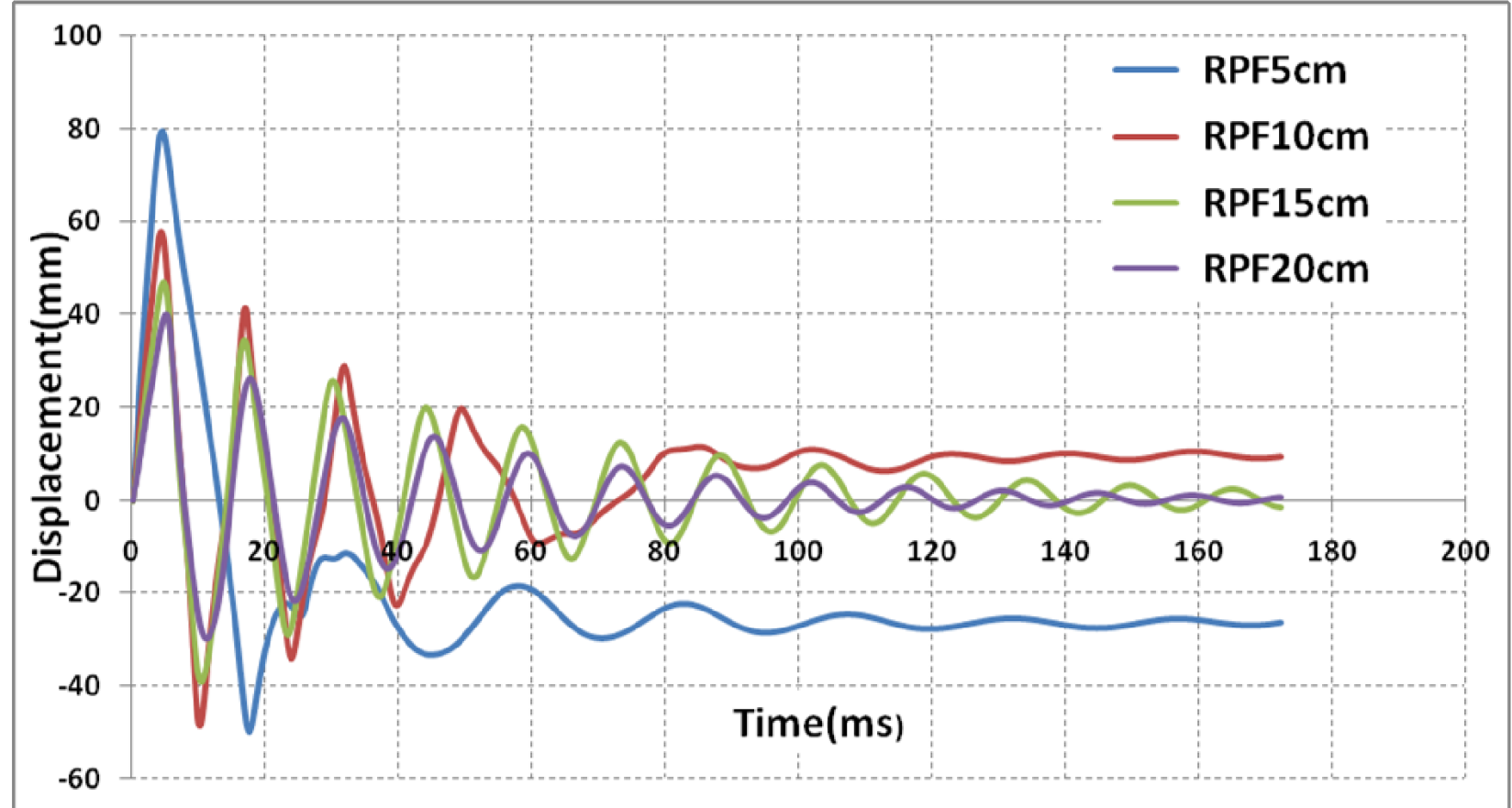

Figure (6): Displacement-time histories of point (1) of RPF core sandwich panels with thickness (5, 10,15 and20) $\mathrm{cm}$ subjected to $10 \mathrm{Kg}$ TNT at standoff $1 \mathrm{~m}$.

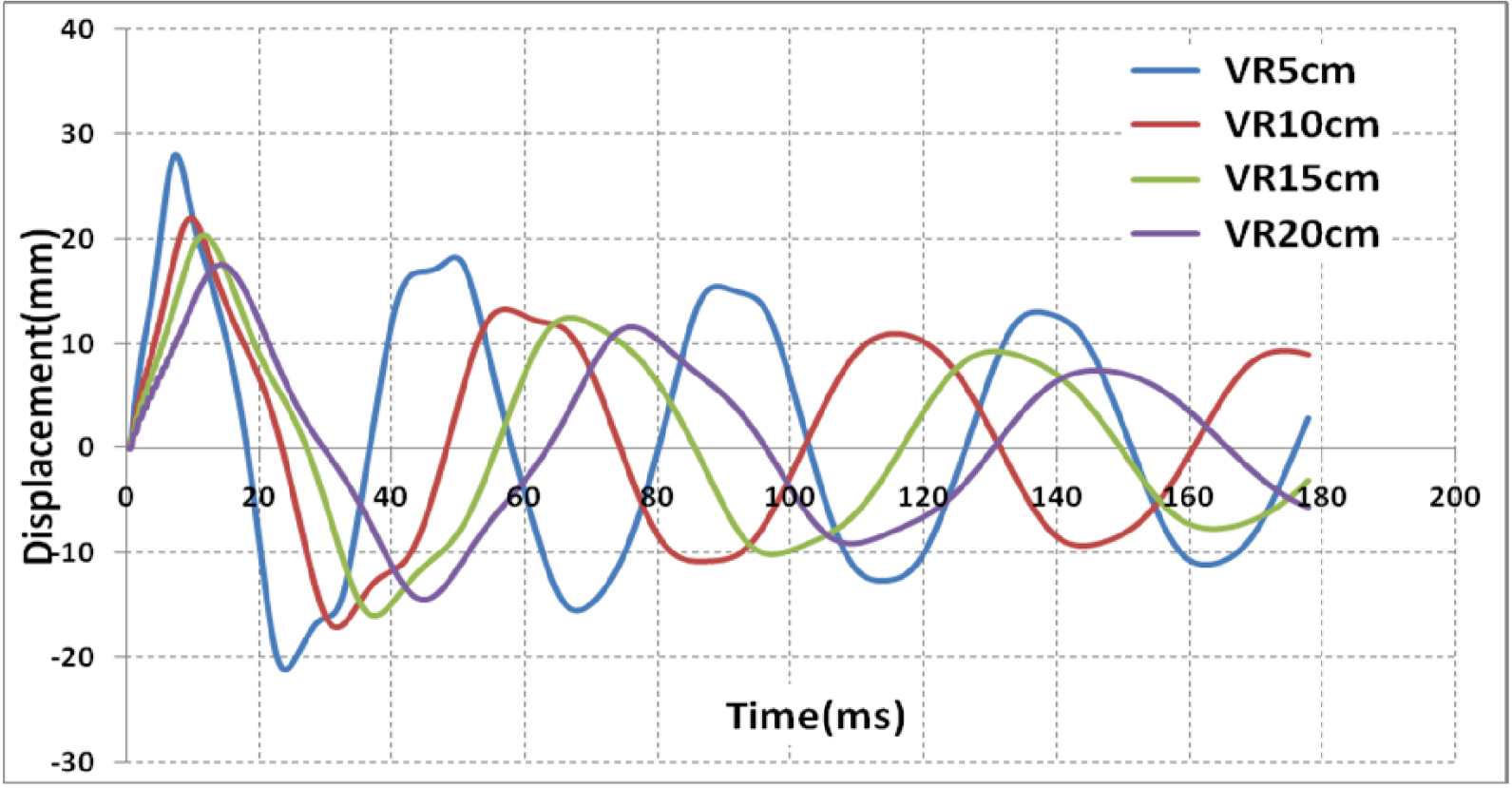

Figure (7): Displacement-time histories of point (1) of RPF sandwich panels with thickness $(5,10$, 15and20) $\mathrm{cm}$ subjected to $1 \mathrm{Kg}$ TNT at standoff $1 \mathrm{~m}$. 


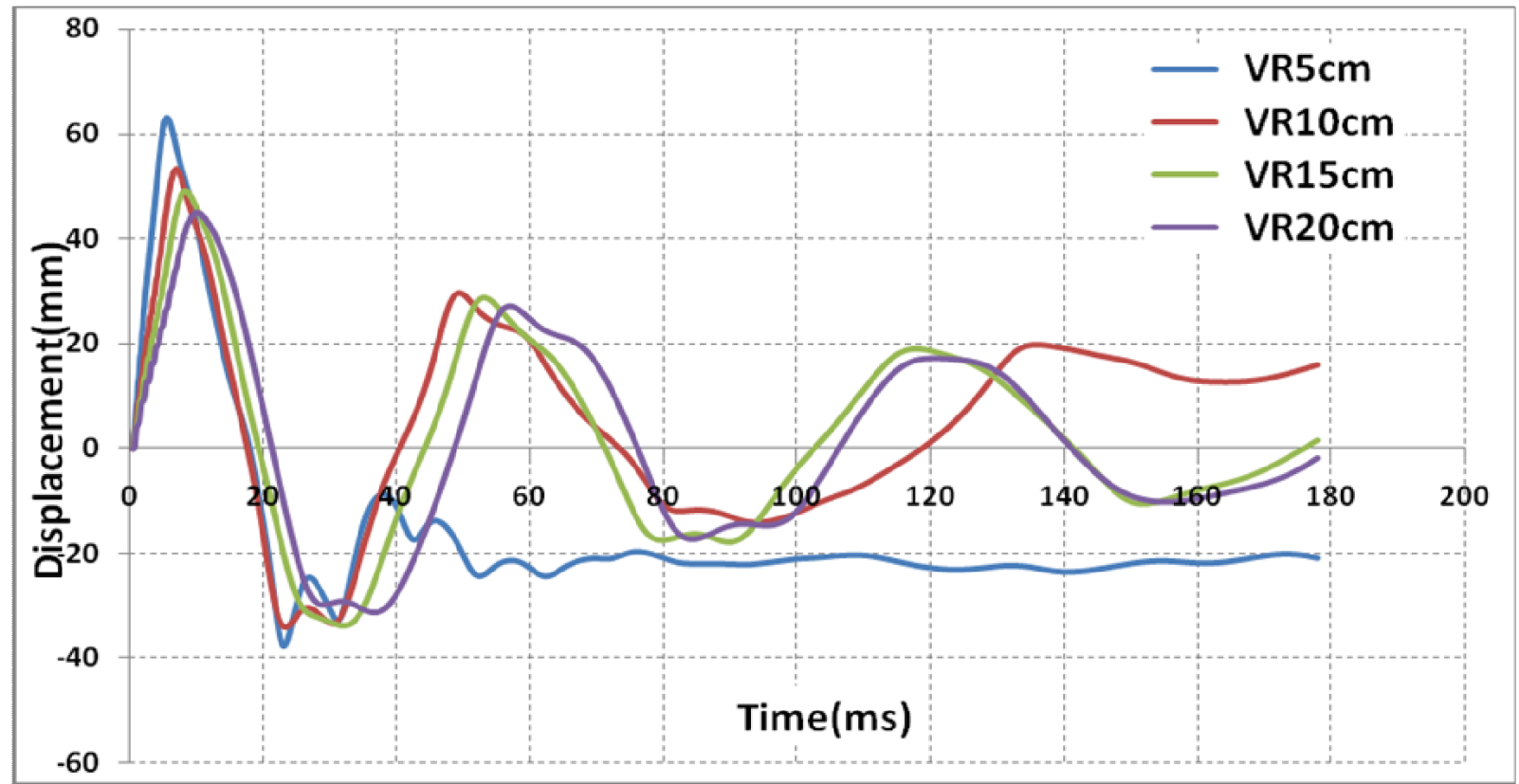

Figure (8): Displacement-time histories of point (1) of RPF sandwich panels with thickness $(5,10$, 15 and20) $\mathrm{cm}$ subjected to $5 \mathrm{Kg}$ TNT at standoff $1 \mathrm{~m}$.

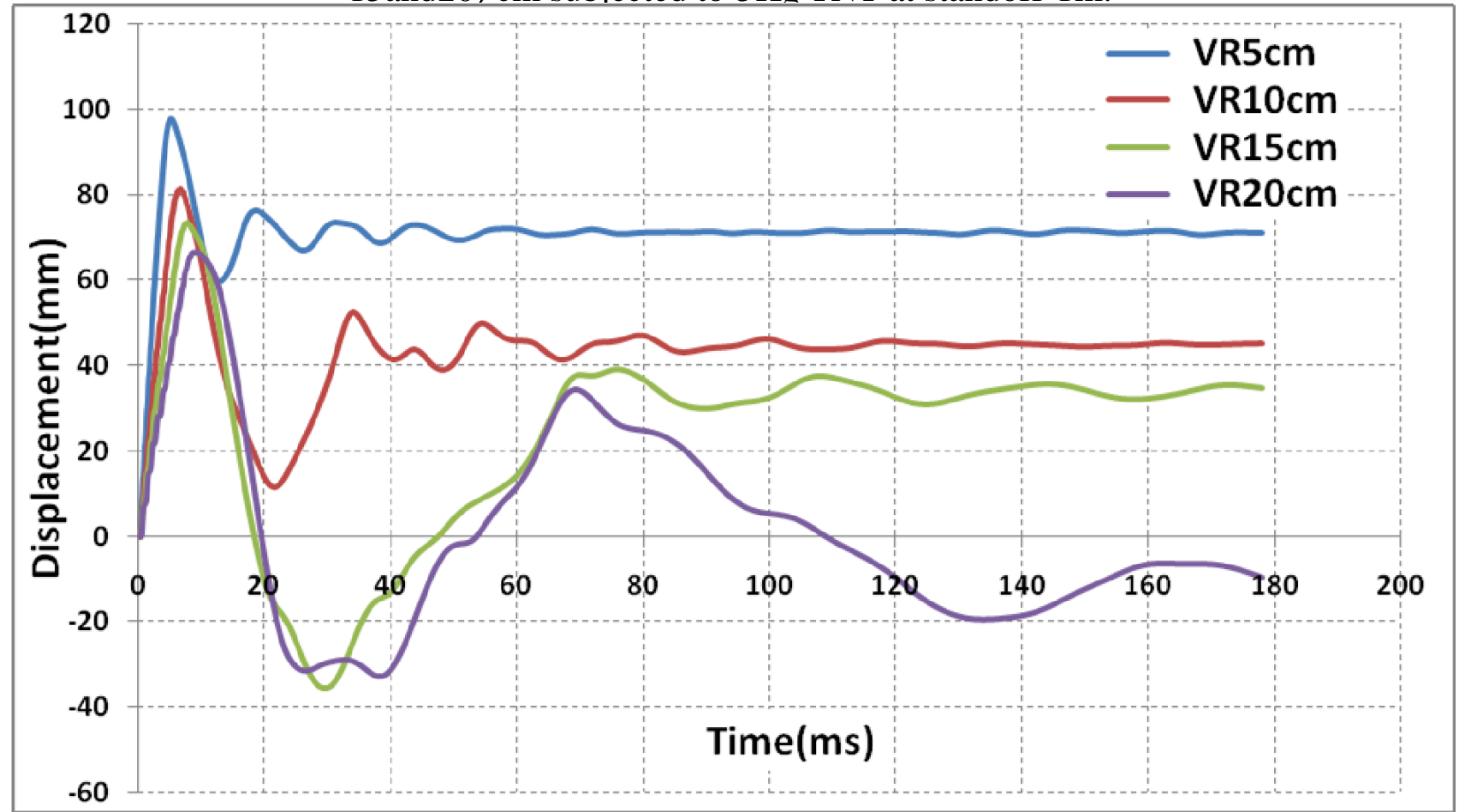

Figure (9): Displacement-time histories of point (1) of RPF core sandwich panels with thickness (5, 10,15 and20) $\mathrm{cm}$ subjected to $10 \mathrm{Kg}$ TNT at standoff $1 \mathrm{~m}$. 


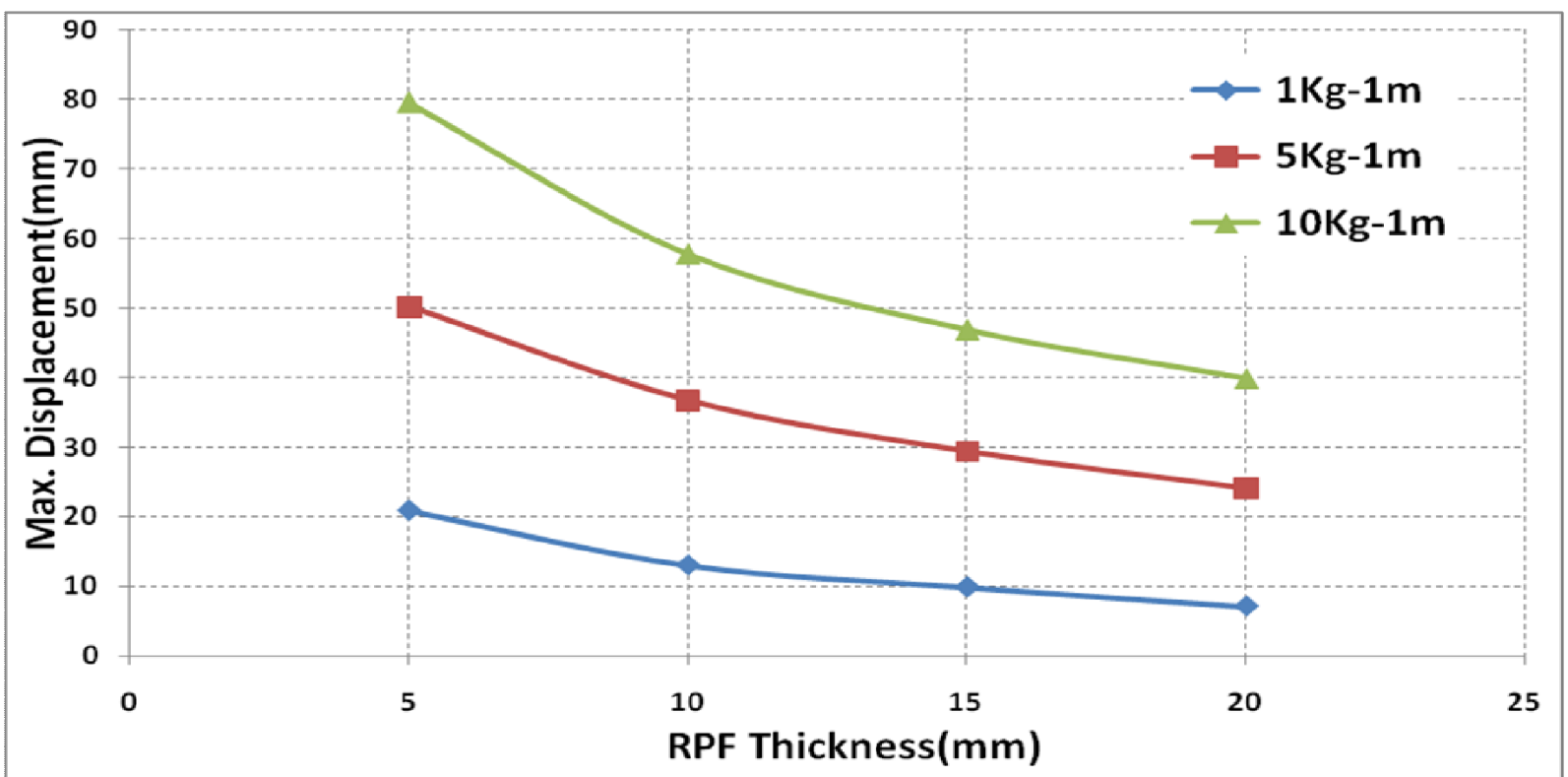

Figure (10): Maximum displacement-thickness chart of point (1) of RPF core sandwich panels with thickness $(5,10,15$ and20) $\mathrm{cm}$ subjected to $(1,5$, and 10$) \mathrm{Kg}$ TNT at standoff $1 \mathrm{~m}$.

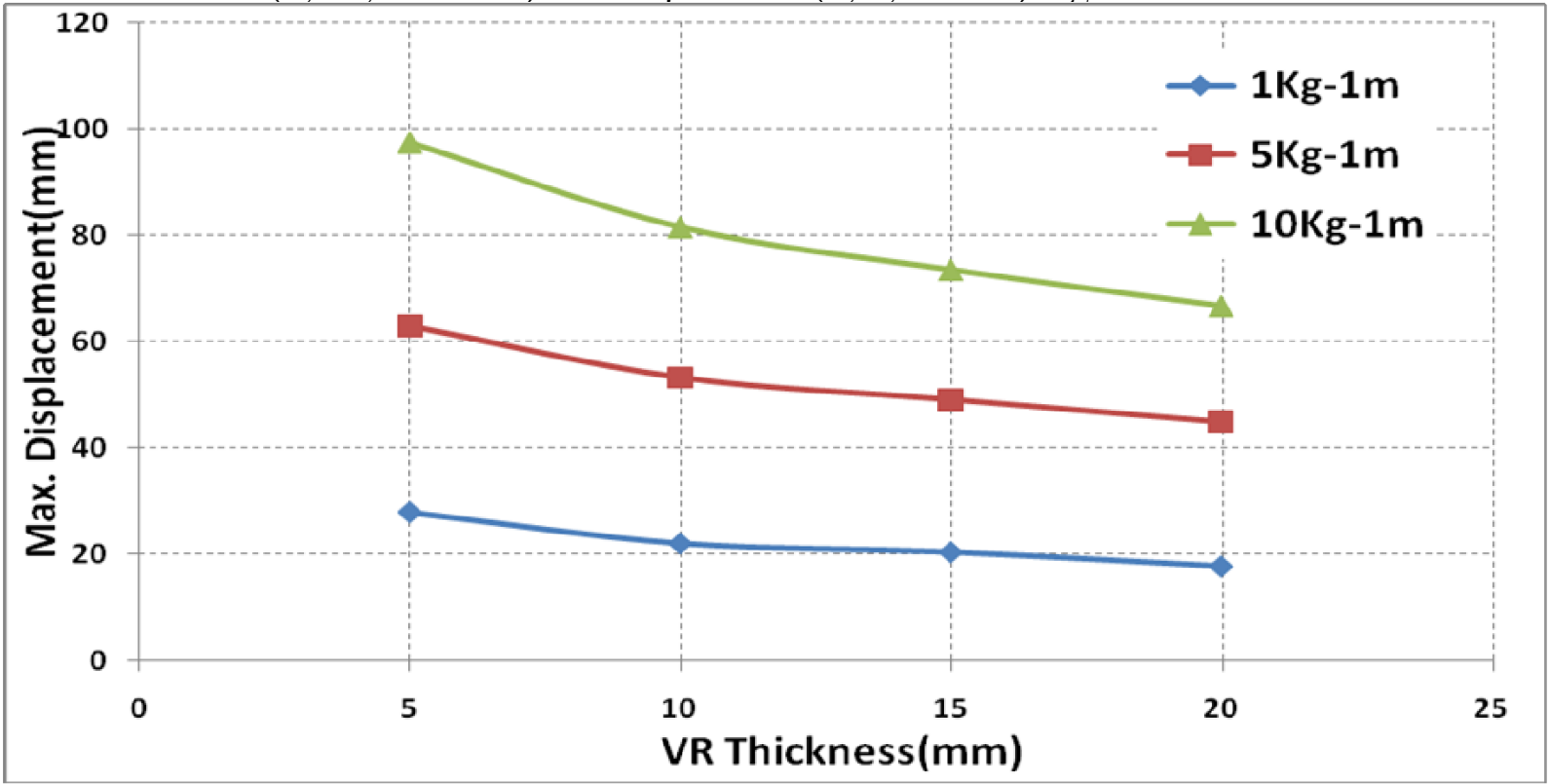

Figure (11): Maximum displacement-thickness chart of point (1) of VR core sandwich panels with thickness $(5,10,15$ and20) cm subjected to $(1,5$, and 10) Kg TNT at standoff $1 \mathrm{~m}$. 


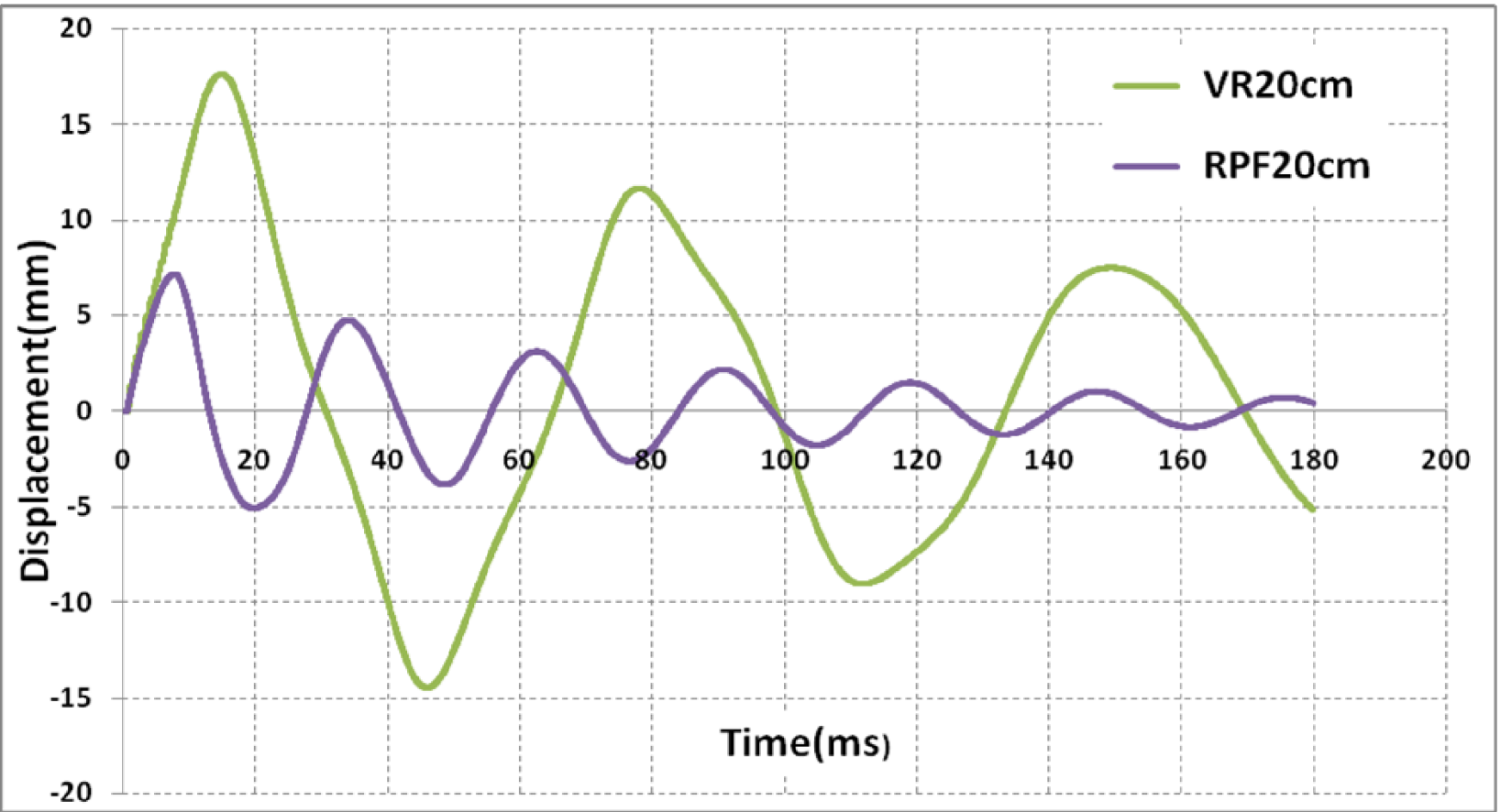

Figure (12): Displacement-time histories of point (1) of RPF and VR sandwich panels with thickness $20 \mathrm{~cm}$ subjected to $1 \mathrm{Kg}$ TNT at standoff $1 \mathrm{~m}$.

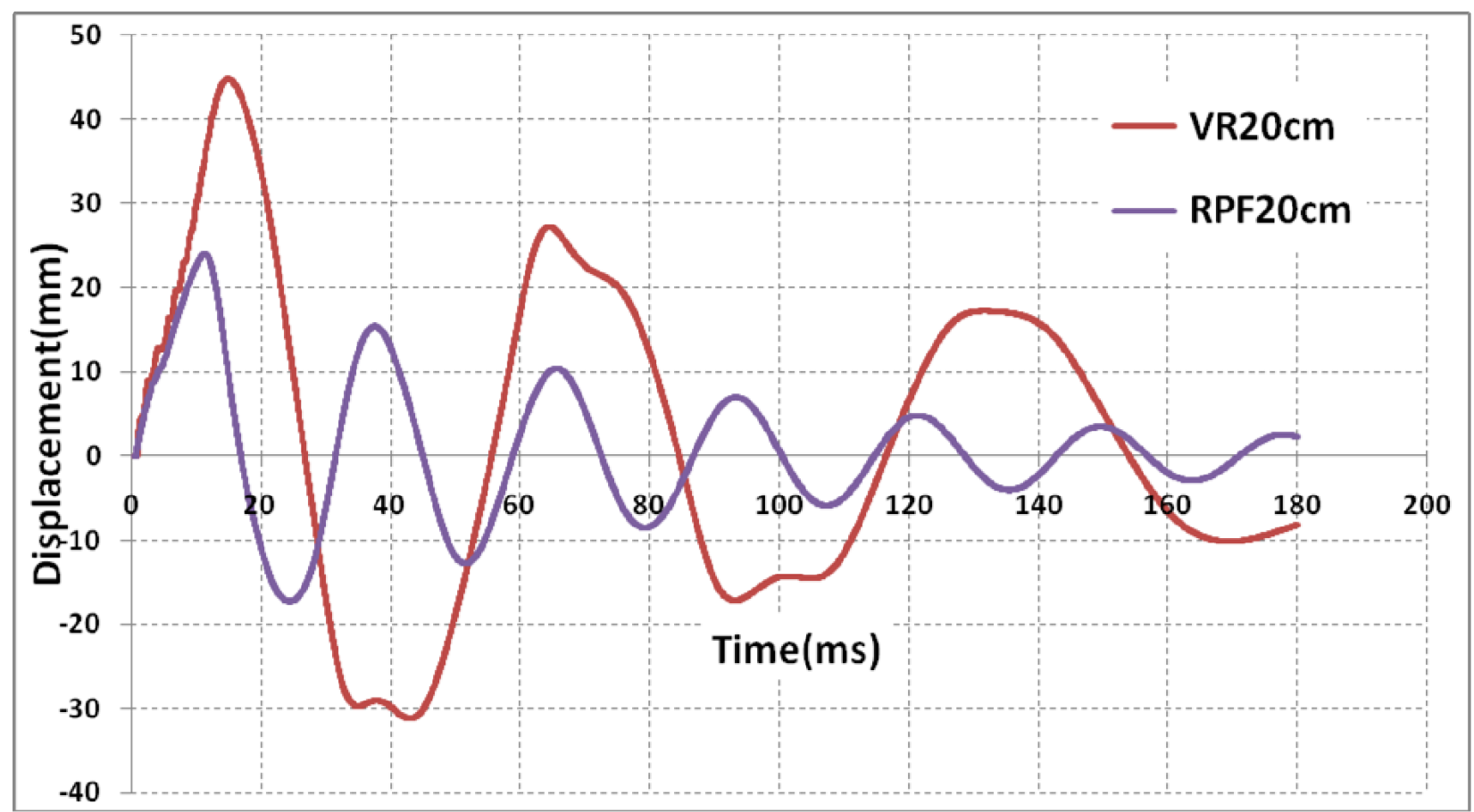

Figure (13): Displacement-time histories of point (1) of RPF and VR sandwich panels with thickness $20 \mathrm{~cm}$ subjected to $5 \mathrm{Kg}$ TNT at standoff $1 \mathrm{~m}$. 


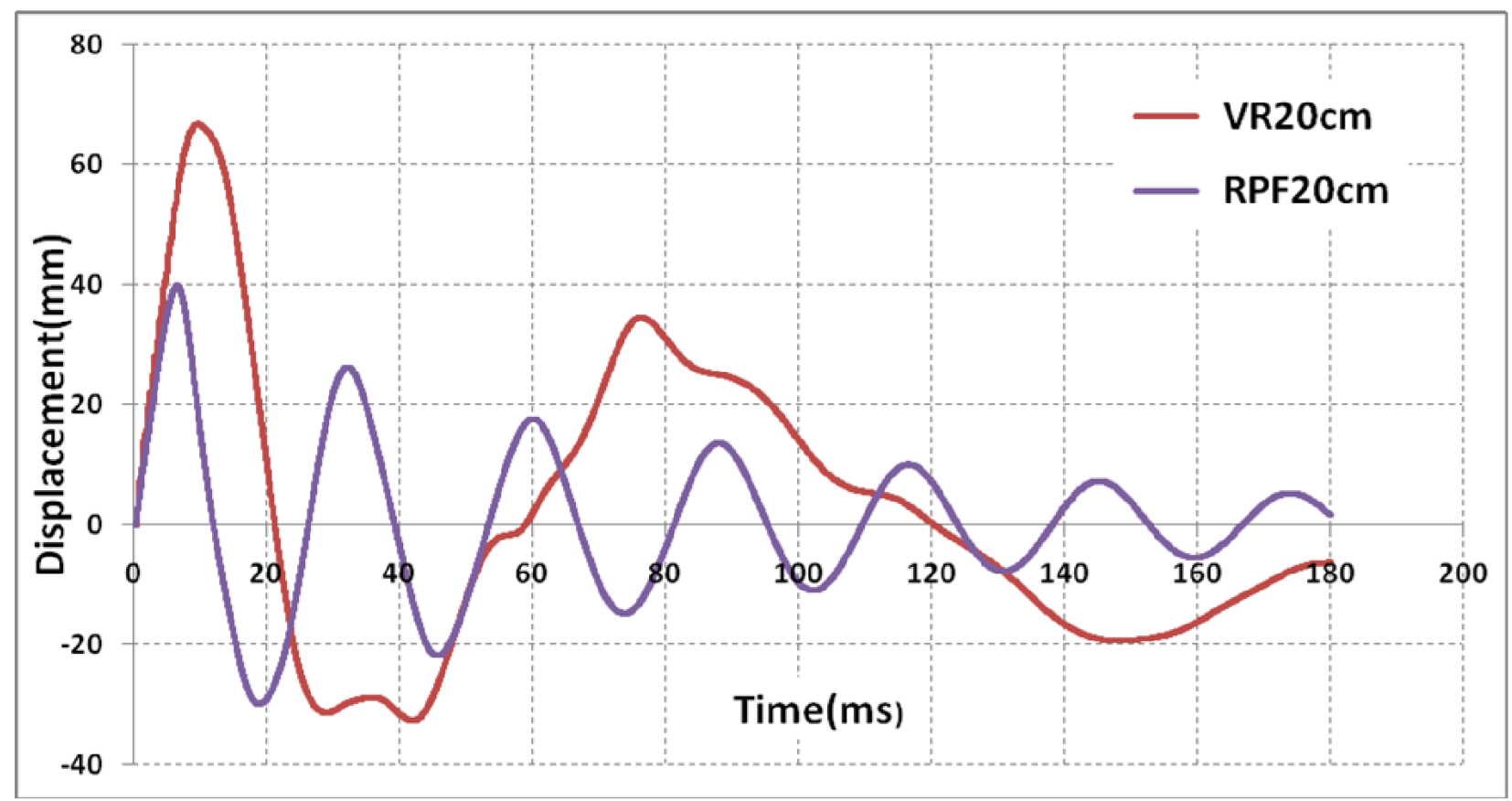

Figure (14): Displacement-time histories of point (1) of RPF and VR sandwich panels with thickness $20 \mathrm{~cm}$ subjected to $10 \mathrm{Kg}$ TNT at standoff $1 \mathrm{~m}$.

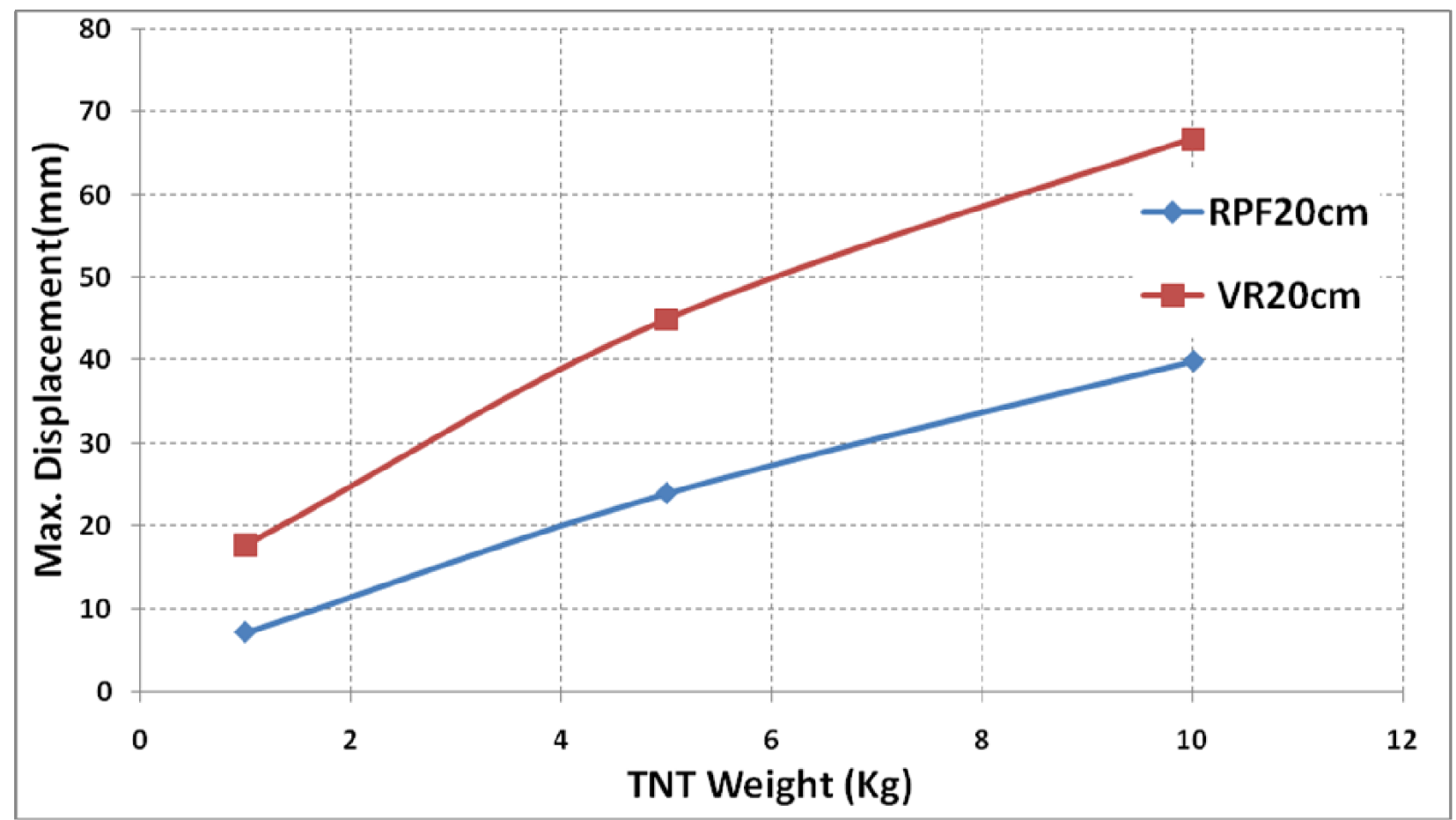

Figure (15): Maximum displacement-TNT Weight chart of point (1) of RPF and VR core sandwich panels with thickness $20 \mathrm{~cm}$ subjected to $(1,5$, and 10) $\mathrm{Kg}$ TNT at standoff $1 \mathrm{~m}$.

Table (1): The percentages of maximum displacement values of RPF sandwich panels with different core thickness. 


\begin{tabular}{|c|c|c|c|c|}
\hline Blast load values & PF5cm & PF10cm & PF15cm & PF20cm \\
\hline 1 Kg TNT & 1 & 0.62 & 0.47 & 0.34 \\
\hline 5Kg TNT & 1 & 0.73 & 0.58 & 0.48 \\
\hline $10 K g$ TNT & 1 & 0.73 & 0.59 & 0.50 \\
\hline
\end{tabular}

Table (2): The percentages of maximum displacement values of VR sandwich panels with different core thickness.

\begin{tabular}{|c|c|c|c|c|}
\hline Blast load values & VR5cm & VR10cm & VR15cm & VR20cm \\
\hline 1Kg TNT & 1 & 0.79 & 0.73 & 0.63 \\
\hline $5 K g$ TNT & 1 & 0.85 & 0.78 & 0.71 \\
\hline $10 K g$ TNT & 1 & 0.83 & 0.75 & 0.68 \\
\hline
\end{tabular}

Table (3): Reduction percentages of maximum displacement values occurred due to the replacement of VR with RPF.

\begin{tabular}{|c|c|c|c|}
\hline Blast load values & $1 \mathrm{Kg}$ TNT & $5 \mathrm{Kg}$ TNT & 10Kg TNT \\
\hline Reduction percentages & $59 \%$ & $49 \%$ & $40 \%$ \\
\hline
\end{tabular}

\section{References}

[1] Beshara, F.B.A., "modeling of blast loading on aboveground structures, internal blast and ground shock", comp. \& struct. Vol.51, No. 5, 1994.

[2] ANSYS “Theory Reference manual”, ANSYS Inc.

[3] Feng Zhu "Impulsive loading of sandwich panels with cellular cores", Sw inburne University of Technology, May 2008.

[4] Nurick GN, Langdon GS, Chi Y and Jacob N. Behaviour of sandwich panels subjected to intense air blast: Part I - experiments. In: Proceedings of 6th International Conference Composite Science and Technology, Durban, South Africa, 2007.

[5] Dong Kwan(David) Lee, B. J. O. T. 2004. Energy Absorbing Sandwich Structures under Blast Loading. 8th International LS-DYNA User Conference.

[6] C.F. Yen, R. S., and B.A. Cheeseman. 2005. Modeling of shock mitigation sandw ich structures for blast protection. The 3rd First International Conference on Structural stability and 
Dynamics.

[7] H. M. El-Fayad, "The Optimum Design of the Tunnels Armored Doors under Blast Effects", Military Technical College, Egypt (2009).

[8] Ronald L. Woodfin, "Results of Experiments on Rigid Polyurethane Foam (RPF) for Protection from Mines", Sandia National Laboratories, Albuquerque.

[9] H. E.MOSTAFA, "Use of Reinforced Rigid Polyurethane Foam for Blast Hazard Mitigation", Department of Civil Engineering, McMaster University, Hamilton, Ontario L8S 4L7, Canada.

[10] Ronald L. Woodfin, "Using Rigid Polyurethane Foams (RPF) for Explosive Blast Energy Absorption in Applications Such as Anti -Terrorist Defenses", Sandia National Laboratories, P. O. Box 5800, Albuquerque.

[11] Sheikh, S. A. and Li, Y. (2007). Design of FRP Confinement for Square Concrete Columns, Engineering Structures, 29 (6): 1074-1083.

[12] Clark, C. J. and Bennett, E. M. (1986). Method for explosive blast control using expanded foam, US Patent 4,589,341-May, 20, 1986.

[13] Johnson, D. R. and Fischer, S. H. (1990). TNT Equivalence of Energetic Materials, Sandia National Laboratories Explosive Components Facility OP-905-0009, (Issue B, Appendix A), p. 7.

[14] Cooper, P. W. and Kurowski, S. R. (1975). Scaling Blast Cavity Diameters in Rigid Foam, Sandia Laboratories Memo of October 6, 1975.

[15] A. A. Mostafa1, "Blast Mitigation using Poly urethane Foam to Retrofit Fortified Sandwich Structures", 8th International Conference on Civil and Architecture Engineering ICCAE , MTC, Cairo, 2010.

[16] Yong Chen, Z.P. Tong, "Experimental investigation on the dynamic response of scaled ship model with rubber sandwich coatings subjected to underwater explosion", International Journal of Impact Engineering 36, 2009 , pp. 318-328.

[17] MARGARET E. ROYLANCE, "The Role of Rubber Modification in Improving High Rate Impact Resistance", Army Materials and Mec hanics Research Center, Watertown. 